\title{
Coding Regions of MSX1 do not Contribute to Non-Syndromic Cleft Lip With/Without Palate in Turkish Patients
}

\author{
Korkut Ulucan ${ }^{\mathrm{a}, \mathrm{i}}$, Arzu Akcay ${ }^{\mathrm{b}}$, Burak Aksoyc, Mehmet Boyraz ${ }^{\mathrm{d}}$, Deniz Kirac ${ }^{\mathrm{e}}$, Deniz Ergec ${ }^{\mathrm{f}}$, \\ Necati Taskıng, Ozhan Ozcelebiler ${ }^{\mathrm{c}}$, Muhsin Konuk ${ }^{\mathrm{a}}$, Teoman Akcay ${ }^{\mathrm{h}}$, A. Ilter Guney ${ }^{\mathrm{f}}$
}

\begin{abstract}
Background: One of the candidate genes for non-syndromic cleft lip with/without palate (NS-CL/P) is muscle segment homeobox 1 (MSX1) gene. MSX1 codes for a homeodomain protein that function as a transcriptional repressor during craniofacial development. In this study, we investigated the contribution of coding regions and exonic-intronic boundaries of $M S X 1$ in Turkish NS-CL/P patients and the gender distribution of NS-CL/P in examined cohort.
\end{abstract}

Methods: We analyzed a total of 100 NS-CL/P Turkish patients, of whom 61 were boy and, 100 non-affected children of whom 44 were boys. Genotyping procedure was assessed by polymerase chain reaction-sequencing protocol. Fisher Exact Analysis was performed to compare the gender difference.

Results: We detected no variations in coding regions and intronicexonic boundaries of $M S X 1$ in both groups. Boys to girls' ratio were

Manuscript accepted for publication January 20, 2014

${ }^{a}$ Department of Molecular Biology and Genetics, Faculty of Engineering and Natural Sciences, Uskudar University; Turkey

${ }^{\mathrm{b}}$ Unit of Bone Marrow Transplantation, Bahcelievler Madical Park

Hospital, Istanbul, Turkey

${ }^{c}$ Department of Reconstructive Surgery, Faculty of Medicine, Marmara

University, Istanbul, Turkey

${ }^{\mathrm{d}}$ Division of Pediatric Endocrinology, Faculty of Medicine, Fatih

University, Ankara, Turkey

${ }^{\mathrm{e}}$ Department of Medical Biology, Faculty of Medicine, Yeditepe University, Istanbul, Turkey

fDepartment of Medical Genetics, Faculty of Medicine, Marmara University, Istanbul, Turkey

${ }^{\mathrm{g}}$ Division of Pediatrics, Kanuni Sultan Suleyman Education and Research Hospital, Turkey

${ }^{\mathrm{h}}$ Division of Pediatric Endocrinology, Kanuni Sultan Suleyman

Education and Research Hospital, Istanbul, Turkey

${ }^{\mathrm{i} C}$ Corresponding author: Korkut Ulucan, Uskudar University, Faculty of Engineering and Natural Sciences, Department of Molecuar Biology and Genetics, Haluk Turksoy Sok. No:14, Altunizade, 34662, Uskudar,

Istanbul, Turkey. Email: korkutulucan@hotmail.com

doi: http://dx.doi.org/10.14740/ijcp136e
1.6 in our patient group. There was a statistically significant gender difference between groups, boys were more effected than girls ( $\mathrm{P}$ $=0.023$ ).

Conclusions: This was the first report including MSX1 in Turkish patients with NS-CL/P. We detected no sequence variations in the coding regions, including the exonic-intronic boundaries of $M S X 1$ in our study population. More comprehensive analysis of $M S X 1$ in Turkish population is required to fulfill MSX1 role for the onset of the anomaly.

Keywords: Cleft lip with/without palate; Congenital; MSX1; Multifactorial; Orofacial clefts

\section{Introduction}

Non-syndromic cleft lip with/without palate (NS-CL/P) (MIM 119530) affects about $1 / 1,000$ live births, and shows wide variability related to geographic distribution, ethnic background and socioeconomic status [1]. Gene-gene and gene-environmental interactions have been implicated in NS-CL/P and several different loci and genes have been associated with NS-CL/P. Studies including monozygotic and dizygotic twins revealed the genetic factors as strong components of orofacial clefts, concordance rate was reported as $40-60 \%$ and $3-5 \%$, for monozygotic and dizygotic twins, respectively [2]. Lack of $100 \%$ concordance in monozygotic twins suggests the environmental factors importance, not the individual's genotype alone is responsible for the formation of orofacial clefts [3].

Recent studies tried to identify the candidate gene functions in orofacial clefts in different populations and the candidate gene list includes the genes like IRF6, muscle segment homeobox 1 (MSX1), TGFB3, FOXE1, FGFR1, FGFR2, FGF8, PDGFC, CRISPLD2, PVRL1, GABRB3, MSX2, SATB2, TBX10, TBX22, GLI2, JAG2, MTHFR, RARA, $L H X 8, S K I$ and $S P R Y 2$ [3]. The great majority and the common conclusions of the studies are no single locus has been clearly emerged as necessary for the onset of NS-CL/P.

MSX1 gene is a member of MSX family and consists 
Table 1. Primer Sequences, Tm Values and the Length of the Amplicons of the Ampolified Exons

\begin{tabular}{llcc}
\hline Exon & Primer (5'-3' direction) & Tm Value & $\begin{array}{l}\text { Amplicon } \\
\text { length (bp) }\end{array}$ \\
\hline Exon 1 & GCCCGGAGCC CATGCCCGGCGG & $60{ }^{\circ} \mathrm{C}$ & 579 \\
CTCCCTCTGCGCCTGGGTTCTGGCT & & 287 \\
Exon 2.1 & GCTGATCATGCTGCTCCAATGCTT & $60^{\circ} \mathrm{C}$ & \\
& TCTTGTAGTCTCTTTGCCTTGGCG & & 381 \\
& CGCCAAGGCAAAGAGACTACAAGA & $58^{\circ} \mathrm{C}$ & \\
\hline
\end{tabular}

of two exons and one intron. Gene encodes a homeodomain protein that functions as a transcriptional repressor during embryogenesis and systems development like craniofacial, limb and nervous [4]. Studies in mice and humans supported the $M S X 1$ as a strong candidate gene in orofacial clefts. Mice that are homozygous for $M S X 1$-null alleles die right after birth and have severe craniofacial abnormalities including cleft palate [5]. Also, mice and humans lacking $M S X 1$ function show non-syndromic clefts of the secondary palate and tooth agenesis [6].

In this study, we aimed to determine the sequence variations in the coding regions of $M S X 1$ regarding to NS-CL/P and indicate the association of it and NS-CL/P that may be etiological in Turkish patients and also to identify the gender difference between patients and controls in the examined individuals.

\section{Materials and Methods}

\section{Subjects}

A total of 100 patients (aged between 4 and 7) without any family history of NS-CL/P and same number of randomly chosen age-matched controls were recruited for the study. All of the individuals enrolled in the study were of Turkish ancestry, without any immigrants. All the patients were operated at Marmara University, Faculty of Medicine, in the department of reconstructive surgery. Of the 100 patients, 61 were boys (61\%) and 39 were girls (39\%) whereas 44 were boys (44\%) and 56 were girls $(56 \%)$ in control group. Detailed information about the subjects and parents were obtained either directly or by telephone calls. Patients who had any other genetic or dental anomalies were excluded from the study. Ethical Committee of Marmara University approved the experimental protocol and the study procedure was in accordance with the principles of the Declaration of Helsinki II. Written informed consents indicating the aim and protocol of the study were taken from one of their parents who were in charge of the child.

\section{Amplification of MSX1 gene exons}

DNA from subjects were isolated from $200 \mu \mathrm{L}$ peripheral blood by using High Pure PCR Template Preparation Kit (Roche, Germany) using the protocol outlined in the manufacturer's guide. For the mutation detection, two exons including exon-intron boundaries of the gene were amplified. Exon 2 was amplified in two overlapping fragments (exon2.1 and 2.2) so as to take better results in sequencing analysis. Table 1 lists the primers used for amplifying procedures, Tm values and the length of the amplicons. PCR amplifications were performed in a total volume of $50 \mu \mathrm{L}$ containing 50 100 ng DNA template in $10 \mathrm{mM}$ Tris- $\mathrm{HCl}$ (pH 8.0), $50 \mathrm{mM}$ $\mathrm{KCl}, 1.5 \mathrm{mM} \mathrm{MgCl}_{2}, 100 \mathrm{mM}$ each of dNTPs, $1.0 \mathrm{U}$ Taq DNA polymerase and $1.0 \mathrm{mM}$ of each primer. The conditions of PCR amplification were as follows: a denaturation step at $94{ }^{\circ} \mathrm{C}$ for 3 min followed by 34 cycles at $94{ }^{\circ} \mathrm{C}$ for 45 sec, Tm values listed in Table 1 for $1 \mathrm{~min}, 72^{\circ} \mathrm{C}$ for $1 \mathrm{~min}$, a final extension at $72{ }^{\circ} \mathrm{C}$ for $7 \mathrm{~min}$. All the amplicons were visualized in $2 \%$ agarose gel with ethidium bromide $(0.2 \mathrm{~g} /$ $\mathrm{mL}$ ) under ultraviolet light.

\section{Sequencing of $M S X 1$ gene}

Amplicons formed by PCR reactions were sequenced by ABI PRISM 310 Genetic Analyzer (Applied Biosystems, USA) in both directions by using the same primers. Sequencing results were compared to wild type $M S X 1$ as stated in Genbank. 
Table 2. Sex Distribution and Statistically Comparison of Patients and Controls

\begin{tabular}{|c|c|c|c|c|c|}
\hline & \multicolumn{2}{|c|}{$\begin{array}{l}\text { Patients } \\
N=100\end{array}$} & \multicolumn{2}{|c|}{$\begin{array}{l}\text { Controls } \\
\mathrm{N}=100\end{array}$} & \multirow[t]{2}{*}{ P value } \\
\hline Sex & Boys & Girls & Boys & Girls & \\
\hline Numbers & 61 & 39 & 44 & 56 & $0.023 *$ \\
\hline
\end{tabular}

${ }^{*} \mathrm{P}<0.05, \mathrm{P}$ value of Fisher Exact Analysis is shown in the table above and accepted as sense.

\section{Statistical analysis}

Statistical analysis was assessed by using SPSS for Windows version 20.0 (SPSS inc., Chicago, IL, USA). The significance in the statistical analyses between the patient and control groups was assessed using the Fisher Exact Analysis. $\mathrm{P}<0.05$ was considered to represent a statistically significant result.

\section{Results}

PCR and sequencing results revealed no mutations in the examined regions of the genes when compared to the MSXI wild type gene of Genbank.

Fisher Exact Analysis was performed in order to compare the gender difference and NS-CL/P. There was a statistically significant difference in genders between patients and control groups. Boys were more affected than girls $(\mathrm{P}=$ $0.023 ; \mathrm{P}<0.05$ is accepted as sense) (Table 2 ). In our patient group, boys to girls' ratio were 1.6.

\section{Discussion}

NS-CL/P is congenital and complex anomaly that do not follow simple dominant-recessive inheritance pattern. Up to 20 genes were assumed to interact multiplicatively to cause oral clefts. Because of the genetic and ethnic heterogeneity property of the NS-CL/P, different population based studies need to be carried out including the candidate genes that are thought to be responsible for the onset of orofacial clefting.

Our study was based on case-control design rather than case-parent study design. The reason that executed us to choose this study design was not having any information about the variations of MSX1 in Turkish population. This study design was reported to be more useful in understanding the role of candidate gene in populations whose population stratification is not clear [7]. And secondly, case-control studies are more sensitive to detect the minimal changes in allele frequency between cases and controls especially when investigating complex genetic disorders and when working with small sample size.

In our study, we detected no sequence variations in the examined regions of $M S X 1$, two exons including intronicexonic boundaries in Turkish NS-CL/P patients. There are some reports that researchers found no MSX1 mutations in patients with clefts $[8,9]$. According to the previous studies, mutations in $M S X 1$ can contribute to NSCL/P as many as $2 \%$ of the total cases $[10,11]$. Some studies reported the mutations and/or polymorphisms do not contribute to the anomaly in the examined populations [12, 13], and some others reported the variations contribute to the anomaly [14, 15]. The unrepeated results from different populations with different ethnicity showed the variability nature of $M S X 1$ for the onset of NS-CL/P.

Due to some reasons, we were unable to detect any variations in our patients. We recruited $100 \mathrm{NS}-\mathrm{CL} / \mathrm{P}$ unrelated patients having no family history of any genetical disease. As this anomaly is believed to be multigenic, $M S X 1$ may not be the candidate gene for this phenotype in our patients. $M S X 1$ protein interacts with its downstream molecules like Dlx, Lhx2, Bmps and TATA binding proteins during palatogenesis [16]. Variations in these genes and proteins can also cause orofacial clefts or variations in promoter or in intron that can affect splicing can cause anomaly, although the coding sequences are proper. Epigenetic factors, which cannot be detected by simple exon sequencing, can also alter gene function and these may be the reason why we couldn't find an association between MSX1 and NS-CL/P in our study group.

When we compare the gender differences between patients and controls, we found that NS-CL/P was statistically higher in boys $(\mathrm{P}=0.023)$. The ratio of boys to girls was 1.6 in our study cohort. Our results supported some studies that were carried out in different populations $[17,18]$. They all reported male to female ratios were bigger than 1, indicating $\mathrm{CL} / \mathrm{P}$ has more incidences in boys. However, Elliot et al [19] could not find any gender difference for orofacial clefts in Zambia population and Suleiman et al [20] reported a higher incidence of girls in Sudan population. It is quite difficult to make a precise decision about the gender distribution in 
our study, although there is a statistically difference between groups. In order to make a precise decision, extended numbers of patients and controls should be examined. One explanation for this condition may be explained as the number of the boys in patients group was higher than the girls and the number of the boys in control group was lower than the girls, although the patients and the controls were enrolled in the study randomly.

This first study, including Turkish patients and MSX1 in the etiology of NS-CL/P does not allow us to make decisive proposal. Recently we published a family having members with NS-CL/P and in this family, intronic CA repeats may be the causing factor for the onset of the anomaly [21].

It is hard to identify the candidate gene functions in multi-factorial inheritance patterns. As a result of this status, a large and different population analysis including case- control subjects are needed to identify the candidate genes' roles for the onset of diseases. Although we detected no variations in the coding regions of $M S X 1, M S X 1$ and its interacting genes might play an important role in the etiology of orofacial clefts. Analyzing the whole gene and identifying intronic CA repeats will be the focus of our further studies.

\section{References}

1. Carinci F, Scapoli L, Palmieri A, Zollino I, Pezzetti F. Human genetic factors in nonsyndromic cleft lip and palate: an update. Int J Pediatr Otorhinolaryngol. 2007;71(10):1509-1519.

2. Jugessur A, Farlie PG, Kilpatrick N. The genetics of isolated orofacial clefts: from genotypes to subphenotypes. Oral Dis. 2009; 15(7):437-453.

3. Murray JC. Gene/environment causes of cleft lip and/or palate. Clin Genet. 2002;61(4):248-256.

4. Catron KM, Wang H, Hu G, Shen MM, Abate-Shen C. Comparison of MSX-1 and MSX-2 suggests a molecular basis for functional redundancy. Mech Dev. 1996;55(2):185-199.

5. Satokata I, Maas R. Msx1 deficient mice exhibit cleft palate and abnormalities of craniofacial and tooth development. Nat Genet. 1994;6(4):348-356.

6. Vastardis H, Karimbux N, Guthua SW, Seidman JG, Seidman CE. A human MSX1 homeodomain missense mutation causes selective tooth agenesis. Nat Genet. 1996;13(4):417-421.

7. Khoury MJ. Human genome epidemiology: translating advances in human genetics into population-based data for medicine and public health. Genet Med. 1999;1(3):71-73.
8. Modesto A, Moreno LM, Krahn K, King S, Lidral AC. MSX1 and Orofacial Clefting with and without Tooth Agenesis. J Dental Res. 2006; 85: 542-547.

9. De Muynck S, Schollen E, Matthijs G, Verdonck A, Devriendt K, Carels C. A novel MSX1 mutation in hypodontia. Am J Med Genet A. 2004;128A(4):401-403.

10. Tongkobpetch S, Siriwan P, Shotelersuk V. MSX1 mutations contribute to nonsyndromic cleft lip in a Thai population. J Hum Genet. 2006;51(8):671-676.

11. Suzuki Y, Jezewski PA, Machida J, Watanabe Y, Shi M, Cooper ME, Viet le T, et al. In a Vietnamese population, MSX1 variants contribute to cleft lip and palate. Genet Med. 2004;6(3):117-125.

12. Vieira AR, Avila JR, Daack-Hirsch S, Dragan E, Felix TM, Rahimov F, Harrington J, et al. Medical sequencing of candidate genes for nonsyndromic cleft lip and palate. PLoS Genet. 2005;1(6):e64.

13. Lace B, Vasiljeva I, Dundure I, Barkane B, Akota I, Krumina A. Mutation analysis of the MSX1 gene exons and intron in patients with nonsyndromic cleft lip and palate. Stomatologija. 2006;8(1):21-24.

14. Jagomagi T, Nikopensius T, Krjutskov K, Tammekivi V, Viltrop T, Saag M, Metspalu A. MTHFR and MSX1 contribute to the risk of nonsyndromic cleft lip/palate. Eur J Oral Sci. 2010;118(3):213-220.

15. Salahshourifar I, Halim AS, Wan Sulaiman WA, Zilfalil BA. Contribution of MSX1 variants to the risk of nonsyndromic cleft lip and palate in a Malay population. J Hum Genet. 2011;56(11):755-758.

16. Bendall AJ, Abate-Shen C. Roles for Msx and Dlx homeoproteins in vertebrate development. Gene. 2000;247(1-2):17-31.

17. Li Z, Ren A, Liu J, Zhang L, Ye R, Li S. High prevalence of orofacial clefts in Shanxi Province in northern China, 2003-2004. Am J Med Genet A. 2008;146A(20):26372643.

18. Rajabian $\mathrm{MH}$, Aghaei S. Cleft lip and palate in southwestern Iran: an epidemiologic study of live births. Ann Saudi Med. 2005;25(5):385-388.

19. Elliott RF, Jovic G, Beveridge M. Seasonal variation and regional distribution of cleft lip and palate in Zambia. Cleft Palate Craniofac J. 2008;45(5):533-538.

20. Suleiman AM, Hamzah ST, Abusalab MA, Samaan KT. Prevalence of cleft lip and palate in a hospitalbased population in the Sudan. Int $\mathrm{J}$ Paediatr Dent. 2005;15(3):185-189.

21. Ulucan K, Akcay A, Taskın N, Akcay T, Konuk M. MSX1 intronic CA repeat polymorphism is associated with non-syndromic cleft lip with/without palate in a Turkish family. Dis Mol Med. 2013; 1:68-71. 